Pacific Journal of Mathematics

MULTIPLIERS AND UNCONDITIONAL CONVERGENCE OF 


\title{
MULTIPLIERS AND UNCONDITIONAL CONVERGENCE OF BIORTHOGONAL EXPANSIONS
}

\author{
W. J. DAvis, D. W. DEAN AND I. Singer
}

We solve in the affirmative a problem raised by $B$. $S$. Mityagin in 1961, namely, we prove that if $\left(x_{n}, f_{n}\right)$ is a biorthogonal system for a Banach space $E$ with $\left(f_{n}\right)$ total over $E$, such that the set of multipliers $M\left(E,\left(x_{n}, f_{n}\right)\right)$ contains all sequences $\left(\varepsilon_{i}\right)$ with $\varepsilon_{i}= \pm 1$ for each $i$, then $\left(x_{n}\right)$ is an unconditional basis for $E$.

Let $E$ be a Banach space, and let $\left(x_{n}, f_{n}\right)$ be a biorthogonal system for $E$ (i.e., $\left(x_{n}\right) \subset E,\left(f_{n}\right) \subset E^{*}$ and $\left.f_{n}\left(x_{m}\right)=\delta_{n m}\right)$ which has $\left(f_{n}\right)$ total over $E$ (i.e., $f_{n}(x)=0$ for all $n$ implies $x=0$ ). A scalar sequence $\left(\gamma_{n}\right)$ is called a multiplier of an element $x$ in $E$ with respect to $\left(x_{n}, f_{n}\right)$ (write $\left(\gamma_{n}\right) \in M\left(x,\left(x_{n}, f_{n}\right)\right)$ ) if there is an element $y$ of $E$ such that $f_{n}(y)=\gamma_{n} f_{n}(x)$ for all $n$ (call this element $\left.x_{\left(\gamma_{n}\right)}\right)$. The set of multipliers for $E$ with respect to $\left(x_{n}, f_{n}\right)$ is

$$
M\left(E,\left(x_{n}, f_{n}\right)\right)=\bigcap\left\{M\left(x,\left(x_{n}, f_{n}\right)\right) \mid x \in E\right\} .
$$

Here we consider the following two problems:

P 1: (Mityagin [6], Kadec-Pelczynski [4], Pelczynski [7]). Let $E$ be separable and suppose that $M\left(E,\left(x_{n}, f_{n}\right)\right)$ contains all sequences $\left(\varepsilon_{i}\right)$ with $\varepsilon_{i}= \pm 1$ for each $i$. Is $\left(x_{n}\right)$ an unconditional basis for $E$ ?

P 2: (Kadec-Pelczynski [4]). Let $E$ be separable and suppose $M\left(x,\left(x_{n}, f_{n}\right)\right)$ contains all sequences $\left(\varepsilon_{i}\right)$ with $\varepsilon_{i}= \pm 1$ for each $i$. Does the formal expansion $\sum_{n} f_{n}(x) x_{n}$ converge unconditionally to $x$ ?

Problem 2 (and hence also problem 1) is known to have an affirmative answer in the following cases [4]:

$1^{\circ}$. $\quad M\left(x,\left(x_{n}, f_{n}\right)\right) \supset m$ (the space of bounded sequences).

$2^{\circ}$. $E$ contains no subspace isomorphic to $c_{0}$ (the space of sequences converging to 0$)$ and $M\left(x,\left(x_{n}, f_{n}\right)\right) \supset c_{0}$.

$3^{\circ}$. $\operatorname{sp}\left(f_{n}\right)\left(=\right.$ linear span of $\left.\left(f_{n}\right)\right)$ is norming (i.e.,

$$
|x|=\sup \left\{|f(x)| \mid f \in \operatorname{sp}\left(f_{n}\right),\|f\| \leqq 1\right\}
$$

defines a norm on $E$ equivalent to the original norm on $E$ ).

Problem 1 is known to have an affirmative answer in the case when $\left[x_{n}\right]=E$, where $\left[x_{n}\right]$ denotes the closed linear span of $\left\{x_{n}\right\}$ ([5]; see also [1], Theorem 3.4, implication $(4) \Rightarrow(3)$ ).

In the present paper we give an affirmative solution for problem 
1. Our method also provides a more elementary proof of $3^{\circ}$ than that given in [4].

THEOREM 1. Let $E$ be a separable Banach space and let $\left(x_{n}, f_{n}\right)$ be a biorthogonal system for $E$ with $\left(f_{n}\right)$ total over $E$. If $M\left(E,\left(x_{n}, f_{n}\right)\right)$ contains all sequences $\left(\varepsilon_{i}\right)$ with $\varepsilon_{i}= \pm 1$ for each $i$, then $\left(x_{n}\right)$ is an unconditional basis for $E$.

If the hypothesis $\left[x_{n}\right]=E$ is added then a much simpler proof of the theorem is obtained (see the Remark following Lemma 3 below).

Lemma 1. $M\left(E,\left(x_{n}, f_{n}\right)\right) \supset\left\{\left(\varepsilon_{i}\right) \mid \varepsilon_{i}= \pm 1\right.$ for all $\left.i\right\}$ if and only if $M\left(E,\left(x_{n}, f_{n}\right)\right) \supset\left\{\left(\varepsilon_{i}\right) \mid \varepsilon_{i}=0\right.$ or 1 for all $\left.i\right\}$.

Proof. Obvious.

Lemma 2. Suppose $\left(\varepsilon_{i}\right) \in M\left(E,\left(x_{n}, f_{n}\right)\right)$, where $\varepsilon_{i}=0$ or 1 for all $i$ and define $S_{\left(\varepsilon_{i}\right)}=E \rightarrow E$ by

$$
S_{\left(\varepsilon_{i}\right)}(x)=x_{\left(\varepsilon_{\imath}\right)} \quad(x \in E) .
$$

Then $S_{\left(\varepsilon_{i}\right)}$ is a continuous linear mapping.

Lemma 2 is well known (see e.g. [8]).

In the particular case when $\varepsilon_{i}=1$ for $i=1, \cdots, n$ and $\varepsilon_{i}=0$ $i=n+1, n+2, \cdots$ we shall use for $S_{\left(\varepsilon_{i}\right)}$ the notation $S_{n}$. Obviously,

$$
S_{n}(x)=\sum_{i=1}^{n} f_{i}(x) x_{i} \quad(x \in E, n=1,2, \cdots) .
$$

If $\sigma$ is a subset of the positive integers, we define the mapping $S_{\sigma}: E \rightarrow E$ by

$$
S_{\sigma}=S_{\left(\varepsilon_{i}\right)},
$$

where $\varepsilon_{i}=1$ for $i \in \sigma$ and $\varepsilon_{i}=0$ for $i \notin \sigma$.

LEMMA 3. Let $\left(x_{n}, f_{n}\right)$ be a biorthogonal system for $E$ (not necessarily separable), with $\left(f_{n}\right)$ total over $E$. If $M\left(E,\left(x_{n}, f_{n}\right)\right)$ contains all sequences $\left(\varepsilon_{i}\right)$ with $\varepsilon_{i}= \pm 1$ for all $i$, then $\left(\left\|S_{n}\right\|\right)$ is bounded.

Consequently, $\left(x_{n}\right)$ is an unconditional basic sequence (i.e., an unconditional basis of its closed linear span $\left.\left[x_{n}\right]\right)$ and hence, if $\left[x_{n}\right]=E$, then $\left(x_{n}\right)$ is an unconditional basis of $E$.

Proof. Assume that $\left(\left\|S_{n}\right\|\right)$ is unbounded. Let $\left(n_{k}\right)$ be an increasing sequence of integers such that $\left\|S_{n_{k}}\right\| \geqq 2^{k}+\left\|S_{n_{k-1}}\right\|$, whence 
$\left\|S_{n_{k}}-S_{n_{k-1}}\right\| \rightarrow \infty$. Let $\left(M_{p} ; p=1,2, \cdots\right)$ be a countable collection of pairwise disjoint, infinite subsets of the positive integers, $I_{k}=$ $\left\{n_{k-1}+1, \cdots, n_{k}\right\}$, and $\sigma_{p}=\bigcup_{k \in M_{p}} I_{k}$. The projection $S_{\sigma_{p}}$ is continuous by Lemma 2. Moreover, if $k$ is in $M_{p}$ and $x$ is in $E$, we have

$$
\begin{aligned}
\left\|\left(S_{n_{k}}-S_{n_{k-1}}\right) x\right\| & =\left\|\sum_{i=n_{k-1}+1}^{n_{k}} f_{i}(x) x_{i}\right\|=\left\|\sum_{i=n_{k-1+1}}^{n_{k}} f_{i}\left(S_{\sigma_{p}} x\right) x_{i}\right\| \\
& \left.=\| S_{n_{k}}-S_{n_{k-1}}\right) S_{\sigma_{p}} x\|\leqq\| S_{n_{k}}-S_{n_{k-1}}\left\|x_{p}\right\| S_{\sigma_{p}}\|\| x \|
\end{aligned}
$$

where

$$
X_{p}=\left\{x \in E \mid f_{j}(x)=0 \quad \text { if } j \notin \sigma_{p}\right\} .
$$

It follows that $\left\|S_{n_{k}}-S_{n_{k-1}}\right\|_{X_{p}}$ is unbounded as $k$ runs through $M_{p}$. Choose $u_{p} \in X_{p}, k_{p} \in M_{p}$ such that $\left\|u_{p}\right\| \leqq 2^{-p}$ and $\left\|\left(S_{n_{k_{p}}}-S_{n_{k_{p}-1}}\right) u_{p}\right\| \geqq 1$. Let $\sigma=\bigcup_{p=1}^{\infty} I_{k_{p}}$. Now $\sigma \cap \sigma_{p}=I_{k_{p}}$ so that if $y_{p} \in X_{p}$ then $f_{i}\left(S_{\sigma} y_{p}\right)=$ $f_{i}\left[\left(S_{n_{k_{p}}}-S_{\left.n_{k_{p}}\right)}\right) y_{p}\right]$ for all $i$, whence $S_{o} y_{p}=\left(S_{n_{k_{p}}}-S_{n_{k_{p}-1}}\right) y_{p}$. Thus $\sum_{p} u_{p}$ converges while $S_{\sigma}\left(\sum_{p} u_{p}\right)=\sum_{p} S_{\sigma}\left(u_{p}\right)=\sum_{p}\left(S_{n_{k_{p}}}-S_{n_{k_{p}}}\right) u_{p}$ doesn't converge, contradicting Lemma 2 , that $S_{\sigma}$ is continuous. Thus $\left(x_{n}\right)$ is [2] a basic sequence. Since the same argument remains valid for every permutation $\left(x_{\rho(n)}\right)$ of $\left(x_{n}\right)$, it follows that $\left(x_{n}\right)$ is an unconditional basic sequence, which completes the proof.

REMARK. One can give a much simpler proof of the fact that under the hypotheses of Lemma 3 we have

$$
\left.\sup _{n}|| S_{n}\right|_{\left[x_{j}\right]} \|<\infty,
$$

whence $\left(x_{n}\right)$ is an unconditional basic sequence (and, if $\left[x_{n}\right]=E$, then $\left(x_{n}\right)$ is an unconditional basis of $\left.E\right)$. Indeed, if (4) does not hold, then there exist increasing sequences of positive integers $\left(p_{n}\right),\left(q_{n}\right)$ with $p_{n-1}+1 \leqq q_{n-1}+1 \leqq p_{n}\left(n=1,2, \cdots ; p_{0}=q_{0}=0\right)$ and a sequence $\left(u_{n}\right)$ with $u_{n} \in\left[x_{q_{n-1}+1}, \cdots, x_{q_{n}}\right](n=1,2, \cdots)$ such that $\left\|S_{p_{n}} u_{n}\right\|=1$, $\left\|u_{n}\right\| \leqq 1 / 2^{n}(n=1,2, \cdots)$, whence $\left(\sum_{j=1}^{n} u_{j}\right)$ is convergent, but for $\sigma=\left\{1, \cdots, p_{1}, q_{1}+1, \cdots, p_{2}, \cdots\right\}$ the sequence $\left(S_{\sigma}\left(\sum_{j=1}^{n} u_{j}\right)\right)=\left(\sum_{j=1}^{n} S_{p_{3}} u_{j}\right)$ is not convergent. Thus, $S_{\sigma}$ is not continuous, which contradicts Lemma 2, completing the proof.

Proof of Theorem 1. We prove that $S_{n} x \rightarrow x$ for each $x$ in $E$. This will prove the theorem by noting that the same proof works to show that each permutation of $\left(x_{n}\right)$ is a basis for $E$, so that $\left(x_{n}\right)$ is an unconditional basis for $E$. Choose $x$ in $E$ such that $\left(S_{n} x\right)$ does not converge (if it converges, its limit must be $x$ by totality of the sequence $\left.\left(f_{n}\right)\right)$. Let $\left(n_{k}\right),\left(m_{k}\right)$ be sequences of integers such that $m_{k}+1 \leqq$ $n_{k} \leqq m_{k+1}$ for all $k$ and such that there is $\varepsilon>0$ with $\left.\varepsilon<\| S_{n_{k}}-S_{m_{k}}\right) x \|$ for all $k$. Let $u_{k}=\left(S_{n_{k}}-S_{m_{k}}\right) x=\sum_{i=m_{k}+1}^{n_{k}} f_{i}(x) x_{i}$. For each sequence $\left(\eta_{i}\right)$ such that $\eta_{i}=1$ or 0 for each $i$ there is an element of $E$, denoted 
here by $\Sigma \eta_{i} u_{i}$, such that $\left(S_{n_{k}}-S_{m_{k}}\right)\left(\Sigma \eta_{i} u_{i}\right)=\eta_{k} u_{k}$ for every $k\left(\Sigma \eta_{i} u_{i}\right.$ is $x_{\left(\varepsilon_{j}\right)}$ where $\varepsilon_{j}=\eta_{k}$ for $m_{k}+1 \leqq j \leqq n_{k}, k=1,2, \cdots$ and 0 for the other $j$ ). Since $E$ is separable, and since the set $\left\{\Sigma \eta_{i} u_{i} \mid \eta_{i}=1\right.$ or 0$\}$ in $E$ is uncountable, there is a sequence $\left(y_{n}\right)_{0}^{\infty}$ with $y_{n}=\Sigma \eta_{i}{ }^{(n)} u_{i}$ such that $y_{n} \neq y_{m}$ if $n \neq m$ and $y_{n} \rightarrow y_{0}=\Sigma \eta_{i}{ }^{(0)} u_{i}$. Let $K$ be a bound on $\left\|\left(S_{n_{k}}-S_{m_{k}}\right)\right\|$ as guaranteed by Lemma 3 . Then for $p$ large, and all $k,\left\|\left(S_{n_{k}}-S_{m_{k}}\right)\left(y_{p}-y_{0}\right)\right\| \leqq K\left\|y_{p}-y_{0}\right\|<\varepsilon$, but

whence

$$
\left(S_{n_{k}}-S_{m_{k}}\right)\left(y_{p}-y_{0}\right)=\left(\eta_{k}^{(p)}-\eta_{k}^{(0)}\right) u_{k},
$$

$$
\left\|\left(S_{n_{k}}-S_{m_{k}}\right)\left(y_{p}-y_{0}\right)\right\|=\left\{\begin{array}{l}
0 \text { if } \eta_{k}^{(p)}=\eta_{k}^{(0)} \\
\left\|u_{k}\right\|\left|\eta_{k}^{(p)}-\eta_{k}^{(0)}\right|=\left\|u_{k}\right\| \text { otherwise. }
\end{array}\right.
$$

Since $y_{p} \neq y_{0}$ for all $p \neq 0$, there is a $k=k(p)$ for which

$$
\left\|\left(S_{n_{k}}-S_{m_{k}}\right)\left(y_{p}-y_{0}\right)\right\|=\left\|u_{k}\right\|>\varepsilon,
$$

which is impossible for large $p$. Therefore $S_{n} x \rightarrow x$, which completes the proof of Theorem 1.

REMARK. Using the same method, one can also give a more elementary proof of the result $3^{\circ}$ mentioned in the Introduction (actually, of a slightly more general result), than that given in [4]. As above, it is sufficient to show that $\left(S_{n} x\right)$ converges. If not, let $\left(n_{k}\right),\left(m_{k}\right), \varepsilon>0$ and $\left(u_{k}\right)$ be as in the above proof. Since $s p\left(f_{n}\right)$ is norming, by a technique of [3], or, equivalently, by [4], p. 311, lemma and p. 317, Lemma 5, we may assume (dropping to subsequences of $\left(n_{k}\right)$ and $\left(m_{k}\right)$ if necessary) that the natural projection $P_{k}$ of $\left[x_{1}, \cdots, x_{n_{k}}\right] \oplus\left[f_{1}, \cdots, f_{m_{k+1}}\right]_{\perp}$ onto $\left[x_{1}, \cdots, x_{n_{k}}\right]$ is of norm $\left\|P_{k}\right\| \leqq C$, where $C>1$ is a constant independent of $k$ (actually, only this projection property is used in the sequel and therefore we obtain a slightly more general result than $3^{\circ}$ ). As in the above proof of Theorem 1 there is an element of $E$, denoted by $\Sigma \eta_{i} u_{i}$, which is in each of the subspaces $\left[x_{1}, \cdots, x_{n_{k}}\right] \oplus\left[f_{1}, \cdots, f_{m_{k+1}}\right]_{1}$, such that $\left(P_{k}-P_{k-1}\right)\left(\Sigma \eta_{i} u_{i}\right)=\eta_{k} u_{k}$. The proof is completed in precisely the same manner as before, where now $P_{k}-P_{k-1}$ take the role of $S_{k_{k}}-S_{m_{k}}$.

Note. After this work had been completed, we have learned of the recent paper of G. F. Bachelis and H. P. Rosenthal "On unconditionally converging series and biorthogonal systems in a Banach space" (to appear in Pacific J. Math), where Problem 2 (and hence also Problem 1) is solved, even with the hypothesis "Let $E$ be separable" replaced by the weaker hypothesis "Let $E$ contain no subspace isomorphic to $m$ ". However, our methods are completely different and use more elementary tools. 


\section{REFERENCES}

1. G. F. Bachelis, Homomorphisms of annihilator Banach algebras, Pacific J. Math., 25 (1968), 229-247.

2. M. M. Day, Normed Linear Spaces, Springer-Verlag, 1962.

3. - On the basis problem in normed spaces, Proc. Amer. Math. Soc., 13 (1962), $655-658$.

4. M. I. Kadec and A. Pelczynski, Basic sequences, biorthogonal systems and norming sets in Banach and Frechet spaces, Studia Math. 25 (1965), 297-323 (Russian).

5. E. R. Lorch, Bicontinuous linear transformations in certain vector spaces, Bull. Amer. Math. Soc., 45 (1939), 564-569.

6. B. S. Mityagin, Approximative dimension and bases in nuclear spaces, Uspehi Matem. Nauk. 16, 4(100) (1961), 63-132 (Russian).

7. A. Pelczynski, Some problems in functional analysis, Lecture notes, L.S.U. (1966).

8. S. Yamazaki, Normed rings and unconditional bases in Banach spaces, Sci. Pap. Coll. Gen. Educ. Univ. Tokyo, 14 (1964), 1-10.

Received April 3, 1970. The first two authors were supported in part by NSF grants GP-14021 and GP-6023, respectively. The third author was on leave from the Institute of Mathematics of the Romanian Academy of Sciences, Bucharest.

Ohio State University

AND

Institute of Mathematics of the ACAdemy, Bucharest 



\section{PACIFIC JOURNAL OF MATHEMATICS}

\section{EDITORS}

H. SAMELSON

Stanford University

Stanford, California 94305

C. R. Новву

University of Washington

Seattle, Washington 98105
J. DUGundJI

Department of Mathematics

University of Southern California

Los Angeles, California 90007

RICHARD ARENS

University of California

Los Angeles, California 90024

\section{ASSOCIATE EDITORS}
E. F. BECKENBACH
B. H. NeumanN
F. WOLF
K. YOSHIDA

\section{SUPPORTING INSTITUTIONS}
UNIVERSITY OF BRITISH COLUMBIA
CALIFORNIA INSTITUTE OF TECHNOLOGY
UNIVERSITY OF CALIFORNIA
MONTANA STATE UNIVERSITY
UNIVERSITY OF NEVADA
NEW MEXICO STATE UNIVERSITY
OREGON STATE UNIVERSITY
UNIVERSITY OF OREGON
OSAKA UNIVERSITY
UNIVERSITY OF SOUTHERN CALIFORNIA
STANFORD UNIVERSITY
UNIVERSITY OF TOKYO
UNIVERSITY OF UTAH
WASHINGTON STATE UNIVERSITY
UNIVERSITY OF WASHINGTON
AMERICAN MATHEMATICAL SOCIETY CHEVRON RESEARCH CORPORATION TRW SYSTEMS
NAVAL WEAPONS CENTER 


\section{Pacific Journal of Mathematics}

\section{Vol. 37, No. $1 \quad$ January, 1971}

Gregory Frank Bachelis and Haskell Paul Rosenthal, On unconditionally

converging series and biorthogonal systems in a Banach space .........

Richard William Beals, On spectral theory and scattering for elliptic

operators with singular potentials .........................

J. Lennart (John) Berggren, Solvable and supersolvable groups in which every element is conjugate to its inverse ........................ 21

Lindsay Nathan Childs, On covering spaces and Galois extensions ..........

William Jay Davis, David William Dean and Ivan Singer, Multipliers and

unconditional convergence of biorthogonal expansions..............

Leroy John Derr, Triangular matrices with the isoclinal property ............

Paul Erdős, Robert James McEliece and Herbert Taylor, Ramsey bounds for

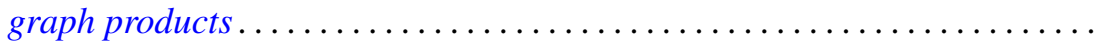

Edward Graham Evans, Jr., On epimorphisms to finitely generated

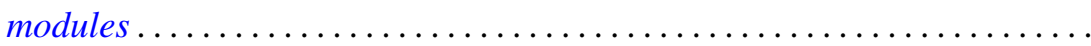

Hector O. Fattorini, The abstract Goursat problem ................. 51

Robert Dutton Fray and David Paul Roselle, Weighted lattice paths .........

Thomas L. Goulding and Augusto H. Ortiz, Structure of semiprime $(p, q)$

radicals ...........................................

E. W. Johnson and J. P. Lediaev, Structure of Noether lattices with join-principal maximal elements ....

David Samuel Kinderlehrer, The regularity of minimal surfaces defined over

slit domains

Alistair H. Lachlan, The transcendental rank of a theory. .

Frank David Lesley, Differentiability of minimal surfaces at the boundary ...

Wolfgang Liebert, Characterization of the endomorphism rings of divisible torsion modules and reduced complete torsion-free modules over complete discrete valuation rings....

Lawrence Carlton Moore, Strictly increasing Riesz norms.

Raymond Moos Redheffer, An inequality for the Hilbert transform ...

James Ted Rogers Jr., Mapping solenoids onto strongly self-entwined,

circle-like continua..........................

Sherman K. Stein, B-sets and planar maps ................... 217

Darrell R. Turnidge, Torsion theories and rings of quotients of Morita

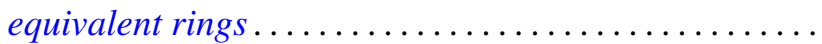

Fred Ustina, The Hausdorff means of double Fourier series and the principle of localization ................................

Stanley Joseph Wertheimer, Quasi-compactness and decompositions for arbitrary relations.

Howard Henry Wicke and John Mays Worrell Jr., On the open continuous images of paracompact $\check{C}$ ech complete spaces... 